\title{
COVID-19 Pandemic Face Masks Pollution: Case Study from an Apulian Hospital
}

\author{
Giovanni Lagioia $^{1}$, Vincenzo Campobasso ${ }^{2}$ and Teodoro Gallucci ${ }^{3}$ \\ 1),2),3) University of Bari Aldo Moro, Bari, Italy. \\ E-mail: giovanni.lagioia@uniba.it; E-mail: vincenzocampobasso@aruba.it \\ E-mail: teodoro.gallucci@uniba.it
}

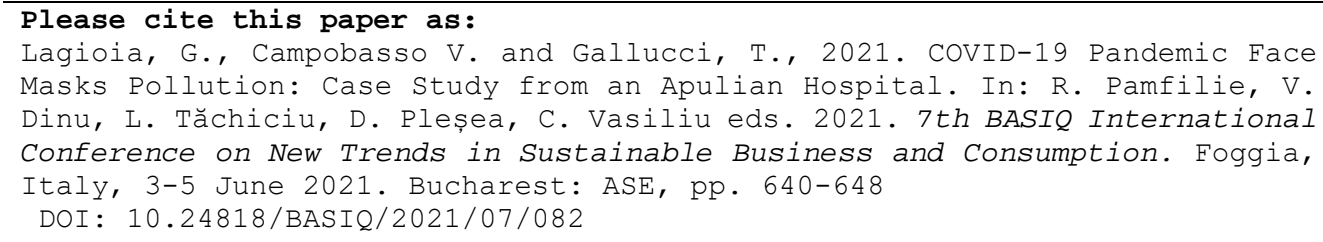

\begin{abstract}
Purpose: The goal is to provide a comprehensive framework about how the COVID-19 pandemic is affecting both plastic pollution and $\mathrm{CO}_{2}$ emissions mainly due to the consumption of face masks in an hospital located in southern Italy, highlighting the $\mathrm{CO}_{2}$ impact as well as the consequences on waste management systems.

Methodology: A detailed literature review research was conducted, scrutinizing governmental websites, technical reports and using engines such as Science Direct, Google Scholar, Elsevier, Inderscience, Scopus. Furthermore, different meetings with the managers of an Apulian hospital have been realized to benchmark the consumption of face masks in the periods before and during the pandemic.

Findings: The research shows that the pandemic has led to an increase of $1,395 \%$ in the use of face masks with consequent impacts both to $\mathrm{CO}_{2}$ emissions, which can be linked to both the production and disposal phases, and to waste management. The most significant value concerns the emissions of $\mathrm{CO}_{2}$ attributable to FFP2 with a rise of $11,735 \%$, compared to the increase in $\mathrm{CO}_{2}$ emissions equal to $1,130 \%$ caused by face surgical masks.

Originality: The case study underlines to what extent the excessive use of face masks contributes to pollution and $\mathrm{CO}_{2}$ emissions linked to both the production, disposal phases, and waste management.

Possible practical implications: This work can be used to identify solutions or alternatives in line with the concepts of sustainability, circular economy and recycling focusing on material alternatives on facial mask production.
\end{abstract}

Keywords: Face mask, Plastic pollution, Covid-19, Waste management, Polypropylene. DOI: 10.24818/BASIQ/2021/07/082

\section{Introduction}

The Covid-19 pandemic in the last year has caused serious economic environmental and social consequences around the world. Scientific literature has highlighted the positive impacts caused by pandemic on the environment as the reduction of greenhouse gases (GHG), nitrogen oxides (NOx), sulfur oxides (SOx) due to less traffic or less industrial production recording, for example, a daily decrease of $\mathrm{CO}_{2}$ emissions equal to minus 17\% in April 2020 if compared with April 2019 (Le Quéré, 2020). At the same time, there are adverse effects mainly related both to the higher number of medical wastes generated within pandemic such as gloves, face mask, gel sanitizer bottles, and the difficulty in their disposal (Saadat, 2020). These medical wastes are mostly made of plastic which first converts into microplastics and then into nano-plastic ending up inland and ocean contaminating the natural ecosystem and altering the food chains. The urgent problem that has emerged is that the over- 
production of plastic medical wastes requires a special effort in their waste management also considering the risk of contamination with pathogens (Parashar and Hait, 2021). The European regulatory framework enforces clear and stringent rules for disposal and treatment of medical waste management. For example, the face masks cannot be classified as plastic materials -even if is composed mainly by plastic materials- but it is classified as an undifferentiated or special waste.

This reflection confirms both the difficulty in the disposal of medical waste or personal protective equipment (PPE) and in their management. These considerations are not limiting the production of plastic medical devices or single-use plastics applications because the perception of health workers is that the single-use of plastic disposable is more hygienic and safer than other materials, such as cotton which requires to be washed and sanitized before to be reused. This has implied that some countries such as the Canada, Portugal, United Kingdom and United States have changed their perception towards the usage of single-use plastics, temporarily revisioning the bans and limitations on single-use plastics during the pandemic period (Parashar and Hait, 2021).

The revisional limitation on plastic to be used for medical purposes, combined with the collapse in the price of oil, due to the reduction in transport activities, has led again to an increase in the production and supply of plastic products (Ecobusiness, 2020). The consequences are clear: industries are returning to produce with virgin plastics, increasing the unsustainability of plastic waste and reducing the recycling rate due to possible contamination of commodities. It can be highlighted that in the countries of Southeast Asia the demand for recycled plastic has decreased by about $30-40 \%$ (BIR, 2020; Klemeš, et al., 2020; Sharma, et al., 2020). A report by the Chinese Ministry of Ecology and Environment reported that during the outbreak in Wuhan- China around $240 \mathrm{t}$ per day of medical waste, mostly plastic, was produced compared to $40 \mathrm{t}$ in the previous period (Klemeš, et al., 2020; WEF, 2020). Considering the face masks production Grand View Research (2020) outlines that 129 billion masks and 65 billion gloves have been used monthly in 2020 and the market has gone from 800 million dollars in 2019 to 166 billion dollars in 2020. As above mentioned, the strong demand for the production of face masks has increased mainly the production of plastic increasing the debate over the environmental consequences. For this reason, it is becoming of utmost importance to verify the production of face masks to make a comprehensive their real contribution to the global warming potential (Liebsch, 2020). The scientific literature in recent years has examined the environmental impacts resulting from the use of face masks.

The environmental impact of surgical masks has been little studied in literature therefore the goal of this research is to provide a comprehensive framework about how the COVID-19 pandemic is affecting both plastic pollution and $\mathrm{CO}_{2}$ emissions mainly due to the consumption of face masks in a hospital located in southern Italy. Preliminary research has been reported analysing the face masks consumption within a hospital located in the Apulian region - Italy - highlighting the $\mathrm{CO}_{2}$ impact as well as the consequences on waste management systems and studying alternative solution to their disposal.

\section{Research methodology}

A detailed literature review research was conducted, scrutinizing governmental websites, technical reports and using engines such as Science Direct, Google Scholar, Elsevier, Inderscience, Scopus. The keywords or terms used for the search were: personal protective equipment (PPE), plastic pollution and Covid, waste management of PPE. Furthermore, have been organized different meetings with the managers of an Apulian hospital useful to benchmark the consumption of face masks in the periods before and during the pandemic. To identify the environmental contribution to $\mathrm{CO}_{2}$ emissions, firstly, a detailed analysis of the components of face masks has been studied. Secondly, the evaluation of $\mathrm{CO}_{2}$ emissions has been calculated, according to the different types of face masks used. Finally, the waste management of masks has been analysed.

\section{Results and discussion}

Standard and composition of face masks

Before assessing the environmental impact of face mask production, their main characteristics are reported. There are mainly two types of face masks on the Italian market, distinguished in a) surgical 
face masks and b) filtering face pieces (such as FFP2). For a) the technical standard of reference at the international level is UNI EN 14683:2019: this reference standard does not establish the materials to be used for the production of the masks, but establish the characteristics that face masks must possess; for b), conversely, the technical reference standard is UNI EN 149:2009: this standard classifies the degree of protection from dust, where the numbers 1 indicates low protection $(>80 \%)$, the number 2 indicates medium protection $(>94 \%)$ and number 3 indicates high protection $(>99 \%)$ (Santarsiero, et al, 2020).

Scientific literature identifies polypropylene as the most suitable material for making surgical face masks and filtering facepieces. Polypropylene (PP) is one of the most widely used plastic materials in the world, second only to polyethylene which has a market share of approximately $70 \%$. Polypropylene is a semi-crystalline thermoplastic material that exhibits different mechanical properties according to different chemical characteristics (Akber et al. 2020). Giulio Natta received the Nobel Prize in Chemistry for studying catalysts to produce polypropylene of different tactics. This material is characterized by high tensile strength, high ductility, low density, and excellent thermal resistance to abrasion. It also exhibits low cost to its high properties. It should be emphasized that according to a recent study (Alsabri and Al-Ghamdi, 2020) polypropylene production has a higher environmental impact equal to $1.58 \mathrm{~kg}$ $\mathrm{CO}_{2} / \mathrm{kg}-\mathrm{PP}$, which is embodied in surgical face mask therefore, in the assessment of environmental impacts, it is also necessary to analyse how the emissions of $\mathrm{CO}_{2}$ arise as the use of face masks increases. Tables 1 and 2 report materials composition and weights of facial masks.

Table no. 1. Surgical face mask technical features

\begin{tabular}{ll}
\hline Layers & \\
Total size & $175 \mathrm{~mm}$ X $95 \mathrm{~mm}$ \\
Spunbond weight & $25 \mathrm{~g} / \mathrm{m}^{2}$ \\
Meltblown weight & $30 \mathrm{~g} / \mathrm{m}^{2}$ \\
\hline
\end{tabular}

Nose clip

Material Aluminum coated in PP/PE

Rubber bands

Material Polyester covered in nailon yarn

Source: Information from the datasheet (Available at https://www.gruppogda.it)

Table no. 2. Filtering facepiece composition

Layers

$\begin{array}{ll}\text { Total size } & 168 \mathrm{~mm} \text { X } 108 \mathrm{~mm} \\ \text { Inner spunbond layer weight } & 30 \mathrm{~g} / \mathrm{m}^{2} \\ \text { Outer spunbond layer weight } & 50 \mathrm{~g} / \mathrm{m}^{2} \\ \text { Cotton layer weight } & 40 \mathrm{~g} / \mathrm{m}^{2} \\ \text { Meltblown layer weight } & 55 \mathrm{~g} / \mathrm{m}^{2}\end{array}$

Nose clip

Material $\quad$ Aluminium coated in PP/PE

Rubber bands 
As Table 1 and Table 2 show, the surgical face mask is usually composed by three-layer polypropylene with different characteristics: spunbond layer (outer layer and inner layer) which confers the mechanical resistance to the outer layer and protective function to the inner side; meltblown for the intermediate layer with a filtering function. Conversely, the filtering facepiece (FFP2) has multiple layers. For structural and functional reasons, the surgical face mask and filtering facepiece require various other materials, such as cotton, other plastics and/or metals. Cotton is used for the laces, metals and/or other plastics, like polyethylene (PE), are used for the nose pads, while for the edging, sometimes optional, other polymers are used (Barycka, et al. 2020). It emerges that quantity of materials used as well as the relative quantities in an FFP2 are greater than a surgical face mask and this, as highlighted in the next subparagraph, influences the environmental impacts, both in terms of $\mathrm{CO}_{2}$ emissions than in terms of waste management.

\section{$\mathrm{CO}_{2}$ emissions of face masks}

For the calculation of $\mathrm{CO}_{2}$, the work of Klemes, et al. (2020) was used, in which the $\mathrm{CO}_{2}$ emissions of different types of face masks is reported: the $\mathrm{CO}_{2}$ emissions attributable to a single FFP2 are equal to $0.05 \mathrm{~kg}$, the $\mathrm{CO}_{2}$ emissions attributable to a surgical face mask are equal to $0.059 \mathrm{~kg}$. To compare the consumption data of the masks, the management of a medium-large sized hospital in Apulia was contacted. The hospital has about 450 employees, 100 hospitalized per day and 30,000 hospital services per year, data provided of the consumption of the surgical face masks and FFP2 masks in the periods pre-Covid-19 (March 2019 - February 2020) and Covid-19 (March 2020 - February 2021). The consumption of surgical face masks of the hospital in the pre-Covid-19 period was equal to 10,151 masks, whereas the consumption of FFP2 was equal to 261. In the Covid period, the consumption of surgical face masks passed to 114,719 masks, whereas the consumption of FFP2 passed to 30,623 masks. As above mentioned, figure 1 shows the $\mathrm{CO}_{2}$ emissions (tons) related to the face surgical mask and FFP2, according to Klemes, et al. (2020).



Figure no. 1. Emissions of $\mathrm{CO}_{2}$ (in tons) related to face surgical mask and FFP2 Source: elaborated by the authors

Figure 1 shows how, due to the pandemic, $\mathrm{CO}_{2}$ emissions relating to the production of face masks have increased overall by $1,356 \%$, of $\mathrm{CO}_{2}$ whereas $\mathrm{CO}_{2}$ emissions related to FFP2 masks increased by $11,735 \%$, and those related to surgical face masks increased by $1,130 \%$ : this difference between the increases in emissions relating to the two types of masks is because before the pandemic the FFP2, in the hospital sector, were almost completely unused. The value of $\mathrm{CO}_{2}$ doesn't include the energy consumption and carbon footprint related to other important criteria as disinfection technologies. For this reason, more study is required to offsetting the potential environmental performance risk with adequate concern on the use of alternative materials to replace the PPE. 
Waste management of face masks

The massive use of face masks has been creating a problem in the disposal phase, as well. As above cited, the surgical face mask consists of three layers of polypropylene: the outer and the inner layers of the mask are produced with spunbond technology and the middle layer is produced with meltblown technology. Furthermore, there are other materials that if not adequately treated can create problems in the final disposal.

Table 3 shows the weight of the materials that make up the surgical face mask.

Table no. 3. Weight of the materials of a surgical face mask

\section{Layers}

$\begin{array}{lll}\text { Total size } & 175 \mathrm{x} 95 \mathrm{~mm} & \\ \text { Inner spunbond layer } & \text { Size } & 175 \mathrm{~mm} \text { X } 165 \mathrm{~mm} \\ \text { Weight } & \text { Size } & 0.717 \mathrm{~g} \\ \text { Middle meltblown layer } & \text { Weight } & 175 \mathrm{~mm} \mathrm{X} 165 \mathrm{~mm} \\ & \text { Size } & 0.861 \mathrm{~g} \\ \text { Outer spunbond layer } & \text { Weight } & 175 \mathrm{~mm} \mathrm{X} 185 \mathrm{~mm} \\ & 2.383 \mathrm{~g} & 0.805 \mathrm{~g} \\ \text { Total weight of the layers } & & \\ \text { Other components } & 0.545 \mathrm{~g} \\ \text { Weight of the rubber bands } & 0.230 \mathrm{~g} \\ \text { Weight of the nose clip } & 3.158 \mathrm{~g} \\ \text { Total weight } & \text { Source: elaborated by the authors on the different composition }\end{array}$

It can be seen how the size of the face mask is $175 \mathrm{~mm} \mathrm{X} 185 \mathrm{~mm}$, but this value doesn't consider the edging and the folds. The size of the individual layers isn't equal to each other.

The FFP2 has five layers with different materials: two layers of spunbond, two layers of meltblown and one layer of cotton. Table 4 shows the weight of the materials that make up the filtering facepiece (FFP2).

Table no. 4. Weight of the materials of an FFP2

\begin{tabular}{ll} 
Layers & \\
Weight Inner spunbond layer & $0.5443 \mathrm{~g}$ \\
Weight Meltblown layers (for single layer) & $0.9979 \mathrm{~g}$ \\
Weight Outer spunbond layer & $0.9072 \mathrm{~g}$ \\
Weight Cotton layer & $0.7257 \mathrm{~g}$ \\
Total weight of the layers & $4.173 \mathrm{~g}$ \\
Other components & \\
Weight of the rubber bands & $0.956 \mathrm{~g}$ \\
Weight of the nose clip & $0.573 \mathrm{~g}$ \\
Total weight & $5.702 \mathrm{~g}$ \\
\hline
\end{tabular}


Tables 3 and 4 report the weight of components present in both face masks. It emerges that: a surgical face mask is made of $2.4 \mathrm{~g}$ of PP, $0.23 \mathrm{~g}$ of AL coated in PP/PE and $0.54 \mathrm{~g}$ of PL coated in nylon whereas an FFP2 is made of $3.44 \mathrm{~g}$ of PP, $0.57 \mathrm{~g}$ of AL coated in PP/PE, $0.96 \mathrm{~g}$ of PL coated in nylon and $0.72 \mathrm{~g}$ of cotton. Using the information provided by the hospital located in the Apulia region, it was calculated to what extent the waste deriving from surgical masks increased in the period March 2019 - February 2020 and March 2020 - February 2021.

Table 5 shows the waste materials in the reporting periods due to the Covid-19 pandemic

Table no. 5. The waste generated by the use of face masks in different periods

\begin{tabular}{|c|c|c|c|c|}
\hline & & SURGICAL & FFP2 & TOTAL \\
\hline \multirow{4}{*}{$\begin{array}{l}\text { March } 2019 \\
\text { February } 2020\end{array}$} & PP: & $24.189 \mathrm{~kg}$ & $0.899 \mathrm{~kg}$ & $25.088 \mathrm{~kg}$ \\
\hline & AL coated in PP/PE: & $2.334 \mathrm{~kg}$ & $0.149 \mathrm{~kg}$ & $2.483 \mathrm{~kg}$ \\
\hline & PL coated in Nylon: & $5.532 \mathrm{~kg}$ & $0.249 \mathrm{~kg}$ & $5.781 \mathrm{~kg}$ \\
\hline & Cotton: & $0 \mathrm{~kg}$ & $0.189 \mathrm{~kg}$ & $0.189 \mathrm{~kg}$ \\
\hline \multicolumn{2}{|l|}{ Total waste } & $33,541 \mathrm{~kg}$ & & \\
\hline \multirow{4}{*}{$\begin{array}{l}\text { March } 2020 \\
\text { February } 2021\end{array}$} & PP: & $273.375 \mathrm{~kg}$ & $105.566 \mathrm{~kg}$ & $378.941 \mathrm{~kg}$ \\
\hline & AL coated in PP/PE: & $26.385 \mathrm{~kg}$ & $17.546 \mathrm{~kg}$ & $43.931 \mathrm{~kg}$ \\
\hline & PL coated in Nylon: & $62.521 \mathrm{~kg}$ & $29.275 \mathrm{~kg}$ & $91.796 \mathrm{~kg}$ \\
\hline & Cotton: & $0 \mathrm{~kg}$ & $22.223 \mathrm{~kg}$ & $22.223 \mathrm{~kg}$ \\
\hline \multicolumn{2}{|l|}{ Total waste } & $536,891 \mathrm{~kg}$ & & \\
\hline
\end{tabular}

Data in table 5 show the trend of quantitative waste generated during the pandemic year. In particular, waste generated by face mask disposal as a potential source for microplastic in the hospital passed by $33,541 \mathrm{~kg}$ in the pre-Covid-19 period to $536,891 \mathrm{~kg}$ in the Covid-19 period: this increase is approximately equal to $1,600 \%$. As for $\mathrm{CO}_{2}$ emissions, also in this case the consumption of FFP2 is more decisive with a relative increase of $11,750 \%$. It should be emphasized that the most relevant material, also, in this case, is polypropylene which represents $74 \%$ of the materials in the pre-covid-19 period and $70.58 \%$ in the covid-19 period. This reduction between the two periods is due to a consistent increase in the use of FFP2 masks which contain different materials including cotton, not present in surgical masks, which represents $4.14 \%$ of total waste in the Covid- 19 period compared to $0.56 \%$ of the pre-Covid-19 period.

These data are very interesting because highlights the importance to build up a managerial system for sorting waste. The disposal of face masks, which are considered as "potentially infected material", is outsourced to an external company and required special efforts for a higher practicality response and decision making. Nowadays, the most suitable solution for facial mask disposal is incineration (ISPRA, 2020). This solution will create other environmental issues: to burn 256 masks, $1.39 \mathrm{~kg}$ of $\mathrm{CO}_{2}$ would be released into the atmosphere. Using historical data, we can expect around $75 \%$ of the masks used during this period, as well as other waste related to the pandemic, will end up in landfills or in the seas (Dharmarajetal, 2021).

\section{Conclusions}

Environmental sustainability of face mask highly depends on how is used and treated at the end-of-life. Incorrect management creates more $\mathrm{CO}_{2}$ footprint. The case study shows that during the pandemic year the consumption of facial masks increased from 10,412 to 145,342 pieces. The $\mathrm{CO}_{2}$ emissions associated with the production of face masks increased respectively by $0.61 \mathrm{t}-\mathrm{CO}_{2}$ to $8.30 \mathrm{t}-\mathrm{CO}_{2}$. Another important consideration is the total increase of waste attributable to the users face masks in the Hospital passed by approximatively $33,541 \mathrm{~kg}$ to $536,891 \mathrm{~kg}$. This situation considerably complicates the envi- 
ronmental problem linked to plastics: while recycling or the use of materials with a lower environmental impact is encouraged for plastic bottles, for masks the regulatory and technological limits make it impossible to recycle and reuse this waste.

Recycling face masks is one of the alternatives to reduce plastic pollution. There are two types of recycling: primary recycling, i.e. reusing the product in its original structure, and secondary recycling, in which the face masks are re-melted and reprocessed into various final products (Lackner, 2015). However, considering the costs of a new face mask this would be cheaper and the filtering capacity and quality of the recycled face mask is lower than a new one, so further alternatives should be found (Chua et al., 2020). In light of this, governments have already begun to explore alternative solutions including the reuse, reprocessing, and production of biodegradable masks (Rubio-Romero et al, 2020).

It is important to find environmentally well-disposed options to minimize environmental impacts. In this direction it is very important to focus on innovation converging on more resistant materials. A new type of mask should be designed to better withstand multiple sterilizations cycle using heat, UV treatment, and isopropyl alcohol, including the use of aggressive methods such as boiling.

Another solution is the use of biodegradable face masks as alternative solutions to reduce waste (Glukhikh et al., 2020). Bioplastic and biodegradable polymers are excellent substitutes for polypropylene with good mechanical, physical, and chemical properties at low cost (Samper et al., 2018; Siracusa and Blanco, 2020). Biodegradable plastic reduces $\mathrm{CO}_{2}$ emissions by $30-70 \%$ compared to conventional plastic (Lackner, 2015). Biodegradable polymers can be obtained from different resources such as polysaccharides, proteins, lipids, and microorganisms and natural fibres such as cactus, banana, avocado, lotus, sisal, straw, hemp, corn, bamboo, hemp, coffee, and sugar cane can meet the requirements for making face masks (Ramesh, et al. Al., 2017, Luhar, et al., 2020; Yan, et al., 2016).

Another approach to reusing face masks is to convert them into building materials with different applications. For example, plastic waste was used in a recent study to make sustainable mortars with $75 \%$ recycled plastic as a partial replacement for sand used in the building sector (Aciu et al. 2018). Furthermore, Adlakha in 2020, has emphasised that used face masks can be reused for the production of sustainable bricks, consisting of $52 \%$ of mask waste, $45 \%$ of paper waste, and $3 \%$ of binding substances, with the advantage of a reduction in terms of costs and waste. Therefore, more research is needed to ensure the performance, efficiency, and economy of the building materials or other products produced by this mask that has generated plastic waste.

\section{References}

Alsabri, A. and Al-Ghamdi, S.G., 2020. Carbon footprint and embodied energy of PVC, PE, and PP piping: Perspective on environmental performance. Energy Reports, 6(2020), pp.364-370.

Aciu, C., Ilutiu-Varvara, D.A., Manea, D.L., Orban, Y.A. and Babota, F., 2018. Recycling of plastic waste materials in the composition of ecological mortars. Procedia Manufacturing, 22, pp.274279.

Adlakha, N., 2020. India's 'Recycle Man' makes bricks from discarded face masks. Homes and Gardens, [online] The Hindu, Available at: <https:/www.thehindu.com/life-and-style/homes-and-gardens/binish-desai-has-designed-bricks-made-from-recycled-face-masks-during-covid-19/article32295016.ece> [Accessed 12 March 2021].

Akber, A.S., Khalil, A.B. and Arslan, M., 2020. Extensive use of face masks during COVID-19 pandemic: (micro-)plastic pollution and potential health concerns in the Arabian Peninsula. Saudi journal of biological sciences, 27, pp. 3181-3186.

Barycka, K., Szarpak, L., Filipiak, K.J., Jaguszewski, M., Smereka, J., Ladny, J.R. and Turan, O., 2020. Comparative effectiveness of N95 respirators and surgical/face masks in preventing airborne infections in the era of SARS-CoV2 pandemic: a meta-analysis of randomized trials. Plos one, 15(12), Article number: 0242901.

BIR, 2020. Covid-19 Update: Fragmented Picture for Under-Pressure Recycling Industry, [online] Bureau of International Recycling (BIR) Available at: <https://www.eco-business.org/news- 
press/covid-19-infocenter/item/covid-19-update-fragmented-picture-for-under-pressure-recyclingindustry> [Accessed 1 March 2021].

Chua, M.H., Cheng, W., Goh, S.S., Kong, J., Li, B., Lim, J.Y.C., Mao, L., Wang, S., Xue, K., Yang, L., Ye, E., Zhang, K., Cheong, W.C.D., Tan, B.H., Li, Z., Tan, B.H. and Loh, X.J., 2020. Face Masks in the New COVID-19 Normal: Materials, Testing, and Perspectives. Research, 2020, Article number:7286735.

Dharmaraj, S., Ashokkumar, V., Hariharan S., Manibharathi A., Show P., Chong CT. and Ngamcharussrivichai C., 2021. The COVID-19 pandemic face mask waste: A blooming threat to the marine environment. Chemosphere, 272, Article number: 129601.

Eco-Business, 2020. Coronavirus-induced oil price plunge is hurting the circular economy for plastic, [online] Available at: $<$ https://www.eco-business.com/news/coronavirus-induced-oil-price-plungeis-hurting-the-circular-economy-for-plastic/> [Accessed 22 March 2021].

Glukhikh, V., Buryndin, V.G.., Artyemov, A.V., Savinovskih, A.V., Krivonogov, P.S. and Krivonogova, A.S., 2020. Plastics: physical-and-mechanical properties and biodegradable potential. Foods and Raw Materials, 8(1), pp.149-154.

Grand View Research, 2020. Grand View Research, [online] Available at: $<$ https://www.grandviewresearch.com $\geq$ [Accessed 4 March 2021].

Gruppo GDA, 2021. GDA Group, [online] Available at: <www.gruppogda.it> [Accessed 2 March $2021]$.

Klemeš, J., Van Fan, Y. and Jiang, P., 2020, The energy and environmental footprints of COVID-19 fighting measures e PPE, disinfection, supply chains. Energy, 211, Article number: 118701.

Lackner, M., 2015. Bioplastics. In: John Wiley \& Sons Inc, ed. Kirk-Othmer Encyclopedia of Chemical Technology. [online] Hoboken, NJ, USA: John Wiley \& Sons, Inc. pp.1-41.

Le Quéré, C., Jackson, R.B., Jones, M.W., Smith, A.J., Abernethy, S., Andrew, R.M. and Friedlingstein, P., 2020. Temporary reduction in daily global $\mathrm{CO}_{2}$ emissions during the COVID-19 forced confinement. Nature climate change, 10(7), pp.647-653.

Liebsch, T., 2020. The Rise of the Face Mask: What's the Environmental Impact of 17 Million N95 Masks? [online] Available at: <https://ecochain.com/knowledge/footprint-face-maskscomparison/> [Accessed 4 March 2021].

Luhar, S., Suntharalingam, T., Navaratnam, S., Luhar, I., Thamboo, J., Poologanathan, K. and Gatheeshgar, P., 2020. Sustainable and renewable bio-based natural fibres and its application for 3D printed concrete: a review. Sustainability, 12(24), Article number: 10485.

Munus Medical, 2021. Filtering facepiece composition, [online] Available at: <www.munusmedical.it> [Accessed 2 March 2021].

Parashar, N. and Hait, S., 2021. Plastic in the time on COVID - 19 pandemic: Protector or polluter? Science of the Total Environment, 759, Article number: 144274.

Ramesh, M., Palanikumar, K. and Reddy, K.H., 2017. Plant fibre based bio-composites: Sustainable and renewable green materials. Renewable \& sustainable energy Reviews, 79, pp.558-584.

Rubio-Romero, J.C., Pardo-Ferreira, M. del C., Torrecilla-García, J.A. and Calero-Castro, S., 2020. Disposable masks: disinfection and sterilization for reuse, and non-certified manufacturing, in the face of shortages during the COVID-19 pandemic. Safety science, 129, Article number: 104830.

Saadat, S., Rawtani, D. and Hussain, C.M., 2020. Environmental perspective of COVID - 19. Science of The Total Environment, 728, Article number: 138870.

Samper, M.D., Bertomeu, D., Arrieta, M.P., Ferri, J.M. and López-Martínez, J., 2018. Interference of biodegradable plastics in the polypropylene recycling process. Materials, 11(10), Article number: 1886.

Santarsiero, A., Ciambelli, P., Donsì, G., Quadrini, F., Briancesco, R., D’Alessandro, D. and Fara, G.M., 2020. Face mask. Technical, tecnological and functional characteristics and hygienic-sanitary aspects related to the use of filtering mask in the community. Ann Ig, 32(5), pp.472-520. 


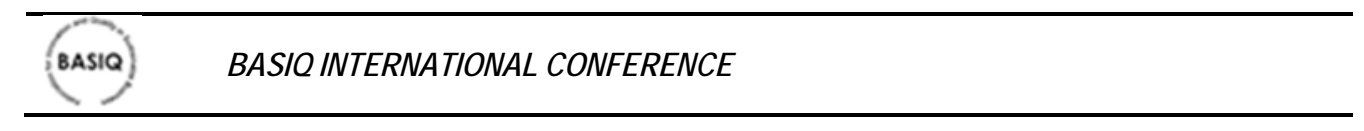

Sharma, H.B., Vanapalli, K.R., Cheela, V.S., Ranjan, V.P., Jaglan, A.K., Dubey, B., Goel, S. and Bhattacharya, J., 2020. Challenges, opportunities, and innovations for effective solid waste management during and post COVID-19 pandemic. Resources conservation and recycling, 162, Article number: 105052 .

Siracusa, V. and Blanco, I., 2020. Bio-Polyethylene (Bio-PE), Bio-Polypropylene (Bio-PP) and BioPolyethylene terephthalate (Bio-PET): recent developments in bio-based polymers analogous to petroleum-derived ones for packaging and engineering applications. Polymers, 12(8), Article number: 1641.

WEF, 2020. The Plastic Pandemic Is Only Getting Worse During COVID-19, [online] World Economic Forum (WEF) Available at: <https:/www.weforum.org/agenda/2020/07/plastic-waste-management-covid19-ppe/> [Accessed 9 March 2021].

Yan, L., Kasal, B. and Huang, L., 2016. A review of recent research on the use of cellulosic fibres, their fibre fabric reinforced cementitious, geo-polymer and polymer composites in civil engineering. Composites Part B-engineering, 92, pp.94-132. 